\title{
Colorimetric Detection of Mycobacterium Tuberculosis ESX-1 Substrate Protein in Clinical Samples Using Au@Pd Nanoparticle- Based Magnetic Enzyme-Linked Immunosorbent Assay
}

Sintayehu Kebede Gurmessa ${ }^{\mathrm{a},}$, Lemma Teshome Tufa ${ }^{\mathrm{b}, \mathrm{c}, \sharp}$, Jeonghyo Kim ${ }^{\mathrm{b}}$, Kang-In Lee ${ }^{\mathrm{a}}$, Young-Mi Kim ${ }^{\mathrm{b}}$, Van Tan Tran $^{\mathrm{b}, \mathrm{d}}$, Huu-Quang Nguyen ${ }^{b}$, Tae Sun Shim ${ }^{\mathrm{e}}$, Jeongkwon Kimº, Tae Jung Park ${ }^{\mathrm{f}}$, Jaebeom Lee ${ }^{\mathrm{b}, *}$, and Hwa-Jung Kimª,*

${ }^{a}$ Department of Microbiology, Medical Science and Infection Control Convergence Research Center, College of Medicine, Chungnam National University, Daejeon, 35015, Republic of Korea

${ }^{\mathrm{b}}$ Department of Chemistry, Chemical Engineering and Applied Chemistry, Chungnam National University, Daejeon, 34134, Republic of Korea

${ }^{\mathrm{c}}$ Department of Chemistry, Adama Science and Technology University, Adama, 1888, Ethiopia

${ }^{\mathrm{d}}$ Faculty of Biotechnology, Chemistry and Environmental Engineering, Phenikaa University, Hanoi, 10000, Viet Nam

${ }^{e}$ Department of Pulmonary and Critical Care Medicine, University of Ulsan, College of Medicine, Asan Medical Center, Seoul 05505, Republic of Korea

fDepartment of Chemistry, Chung-Ang University, 84 Heukseok-ro, Dongjak-gu, Seoul, 06974, Republic of Korea

*Corresponding authors: Hwa-Jung Kim, hjukim@cnu.ac.kr, Jaebeom Lee, nanoleelab@cnu.ac.kr

$¥$ Both the authors contributed equally. 


\section{Introduction}

CFP-10, a major MTB-specific immunogenic antigen secreted during the early phases of infection, has been an ideal candidate for NZ-based immunoassay for TB diagnosis ${ }^{1-2}$. The CFP-10 and ESAT-6 proteins, released by a 6 kDa early secreted antigenic target (ESAT-6) secretion system (ESX-1) of MTB as a complex, sanction the bacteria to resist and evade the host immune response ${ }^{3}$. The ESX-1 secretion system complements CFP-10 to ESAT-6 in a stable 1:1 heterodimeric complex and facilitates their attachment to the host cell surface ${ }^{4}$. These proteins have been used as diagnostic antigens for the interferongamma release assay (IGRA) ${ }^{5}$. However, the test cannot differentiate between active TB and latent TB and exhibit false-negative results in immunocompromised individuals. Similarly, the small quantities of these proteins produced by MTB pose several challenges for their detection from clinical samples in active TB patients ${ }^{6-7}$.

Recently, the modification of an enzyme-linked immunosorbent assay (ELISA) using nanozymes (NZs) gained attention in the antigen-based diagnosis. The modification significantly improves catalytic activity, sensitivity, specificity, stability, and the limit of detection (LOD). Not all NPs possess superior catalytic activity to modify ELISA but can be used to enhance their catalytic potentials. For example, the formation of core-shell bimetallic NZs enhances catalytic efficiency and stability over different $\mathrm{pH}$ and tensile strength values, under controlled physicochemical conditions, such as morphology, size, composition, and surface chemistry ${ }^{8}$. Singh et al. demonstrated that shielding Au with Pd showed excellent peroxidase mimetic activity in malathion detection compared to individual monometallic NZs ${ }^{8}$. Au@Pd NZs as sensing nanoprobes amplified the detection signal of carbohydrate antigen 19-9 by 3-folds compared to horse reddish peroxidase (HRP) in the presence of $\mathrm{H}_{2} \mathrm{O}_{2}{ }^{9}$. The internal interaction between the $\mathrm{Pd}$ shell and the $\mathrm{Au}$ core enhances substrate oxidation while developing more stable $\mathrm{Pd}$ activity after $\mathrm{Pd}$ dispersion on the $\mathrm{Au}$ particles ${ }^{10}$. Thus, bimetallic core-shell Au@Pd nanostructures have demonstrated better catalytic properties than monometallic NPs, since metallization either combines the properties of both metals or the core activates the shell or creates a new property distinct from those available to either metal alone ${ }^{11}$. They have also shown strong peroxidase and catalase-like activity in colorimetric immunoassays, particularly catalyzing the oxidation of $3,3^{\prime}, 5,5^{\prime}-$ tetramethylbenzidine (TMB) in the presence of $\mathrm{H}_{2} \mathrm{O}_{2}$, yielding a colored oxidized form ${ }^{7}, 10$.

\section{Material and Methods}

\section{Materials}

All chemicals and reagents used in the study were of analytical grade. Gold hydrogen tetrachloroaurate (III) trihydrate $\left(\mathrm{HAuCl}_{4} \cdot 3 \mathrm{H}_{2} \mathrm{O}\right)$, trisodium citrate dehydrate $\left(\mathrm{C}_{6} \mathrm{H}_{5} \mathrm{Na}_{3} \mathrm{O}_{7} \cdot 2 \mathrm{H}_{2} \mathrm{O}\right)$, citric acid anhydrous $\left(\mathrm{C}_{6} \mathrm{H}_{8} \mathrm{O}_{7} \cdot \mathrm{H}_{2} \mathrm{O}\right)$, palladium (II) chloride $\left(\mathrm{PdCl}_{2}\right)$, hydrochloric acid $(\mathrm{HCl}), L$-ascorbic acid, ammonium hydroxide $\left(\mathrm{NH}_{4} \mathrm{OH}, 28-30 \mathrm{wt} \%\right)$, tetraethyl orthosilicate (TEOS), (3-aminopropyl) triethoxysilane (APTES), bovine serum albumin (BSA), 3,3',5,5'-tetramethylbenzidine (TMB, T4444), stop reagent for TMB substrate, and phosphate-buffered saline (PBS, $1 \mathrm{M}, \mathrm{pH}$ 7.4) were purchased from Sigma-Aldrich Chemicals (St. Louis, MO). Sulfuric acid (98\%) was purchased from Junsei (Tokyo, Japan) and deionized (DI) water at $18.2 \mathrm{M} \Omega \mathrm{cm}$ was obtained using a Milli-Q system (Millipore, Billerica, MA). Isopropyl- $\beta$-D-thiogalactopyranoside (IPTG) and ultra-filtration discs (3 and $10 \mathrm{kDa}$ ) were purchased from Amicon ${ }^{\mathrm{TM}}$ Bioseparations (Sigma-Aldrich). Dialysis tubing and high retention seamless cellulose tubing with $99.99 \%$ retention were purchased from Sigma-Aldrich. The genetically engineered clones of silica-binding peptide (SBP)-8B3 and gold-binding peptide (GBP)-G3 fusion proteins were obtained from the ChungAng University (Seoul, Korea). Mouse monoclonal anti-6X His tag antibody, sodium dodecyl sulfate (SDS) and polyvinylidene difluoride (PVDF) were obtained from Abcam (Burlingame, CA). All the experiments were carried out using highly pure deionized water $(>18 \mathrm{M} \Omega)$ and PBS. 


\section{Characterizations}

High-angle annular dark-field scanning transmission electron microscopy (HAADF-STEM) and energy dispersive Xray (EDX) analysis was performed using a JEOL ARM200F with STEM Cs corrector operated at $200 \mathrm{kV}$. The absorbance of the samples was measured in microtiter plates using the PerkinElmer Victor 31420 multi-label plate counter. Images of the samples in tubes and microplates were obtained using the Canon EOS Rebel T5 digital camera. Cyclic voltammetry was performed using the Aviumstat electrochemical interface (Eindhoven, Netherlands). A conventional three-electrode system was adopted using a bare or Au@Pd-modified glassy carbon electrode (GCE) as the working electrode, an $\mathrm{Ag} / \mathrm{AgCl}$ reference electrode, and a platinum wire auxiliary electrode. Transmission electron microscopy (TEM) images were acquired using the JEM-2100F field emission electron microscope (JEOL Ltd., Tokyo, Japan). Scanning electron microscopy (SEM) images were captured using the field emission scanning electron microscope (FE-SEM S-4700; Hitachi, Tokyo, Japan). Absorbance spectra were obtained using the UV-Vis spectrophotometer (model 8453, Agilent Technologies Inc., Santa Clara, CA). Conjugation of Au@Pd with GBP-G2 was confirmed by observing a shift in the UV-Vis absorption spectra, percentage intensity difference in the m/z ratio in MALDIMS, and the color change in ELISA.

\section{Preparation of Au NPs, Au@Pd NZs, and silanization of magnetic nanobeads}

$\mathrm{Au}$ NPs were prepared using a modified version of the Turkevich-Frens method ${ }^{14}$. Briefly, $150 \mathrm{~mL}$ of aqueous $\mathrm{HAuCl}_{4} \cdot 3 \mathrm{H}_{2} \mathrm{O}(29.54 \mathrm{~g}, 0.50 \mathrm{mM}$ in $150 \mathrm{~mL})$ was added to a $250 \mathrm{~mL}$ round bottom flask and heated to $100{ }^{\circ} \mathrm{C}$. Subsequently, 7.5 $\mathrm{mL}$ of aqueous trisodium citrate $(40 \mathrm{mM})$ pre-heated to $70{ }^{\circ} \mathrm{C}$ was added to the boiling gold precursor solution under vigorous stirring. The mixture was stirred under reflux for $1 \mathrm{~h}$ and then cooled to $25^{\circ} \mathrm{C}$ and stirred overnight. The Au NPs were collected and stored at $4{ }^{\circ} \mathrm{C}$.

$\mathrm{Au} @ \mathrm{Pd}$ core-shell NPs were synthesized by selective reduction of $\mathrm{H}_{2} \mathrm{PdCl}_{4}$ on $\mathrm{Au} \mathrm{NP}$ seeds in the presence of Lascorbic acid. Briefly, $1.0 \mathrm{mM} \mathrm{H}_{2} \mathrm{PdCl}_{4}$ was prepared by dissolving $17.73 \mathrm{mg}$ of $\mathrm{PdCl}_{2}$ in $2.2 \mathrm{~mL} \mathrm{HCl}(0.1 \mathrm{M})$ under heating and stirring followed by dilution in $100 \mathrm{~mL}$ of DI water to a final concentration of $1.0 \mathrm{mM}$. Then, $30 \mathrm{~mL}$ of the prepared Au NPs was mixed with $14 \mathrm{~mL}$ of $1.0 \mathrm{mM} \mathrm{H}_{2} \mathrm{PdCl}_{4}$ in a $100 \mathrm{~mL}$ conical flask at a temperature of $4{ }^{\circ} \mathrm{C}$. Using single-channel micro-syringe

pump (LP-TJ-3A/W0109-1B, DRIFTON, city, Denmark), $7 \mathrm{~mL}$ of $10 \mathrm{mM}$ L-ascorbic acid was infused at a linear speed of 3.5 $\mathrm{mL} \mathrm{h}$. Silanization of the monodispersed $\mathrm{Fe}_{3} \mathrm{O}_{4}$ magnetic nanobeads (MNBs) purchased from AMO Life Science Inc. (AmoMagTM, Kimpo, Korea) was performed as previously reported ${ }^{12}$. 
Supplementary Figures and Tables

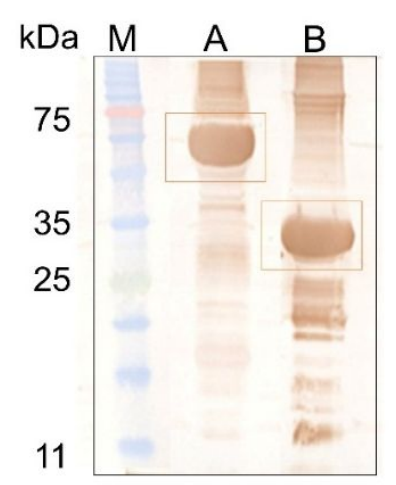

Figure S1. Western blot of the two antibodies used for sandwich ELISA. (A) $63 \mathrm{kDa}$ SBP-G3 IgG. (B) $28 \mathrm{kDa}$ GBP-G2 IgG antibody. (M-Marker)
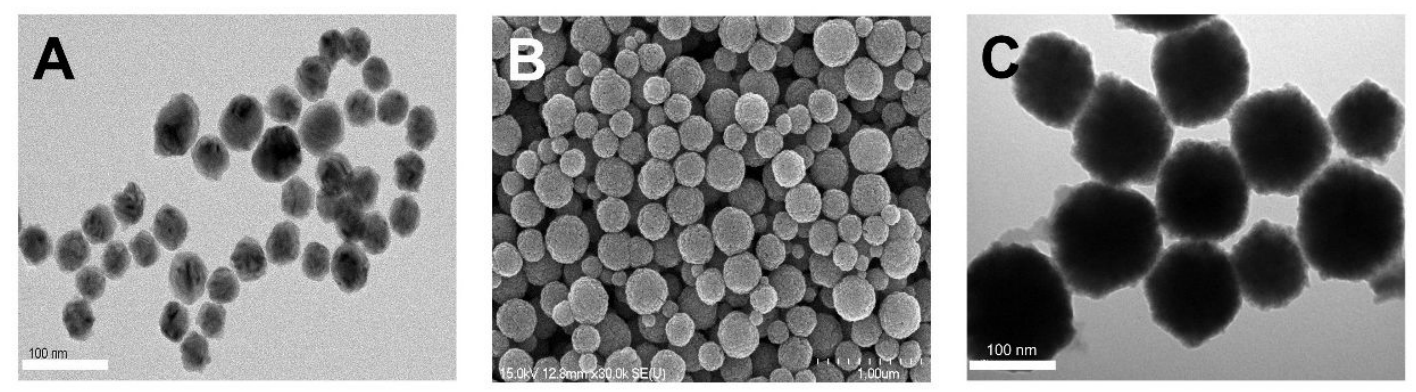

Figure S2. Structural and compositional analysis. (A) HRTEM image of the Au@Pd NZs. (B) SEM images of Fe $\mathrm{O}_{4} \mathrm{NPs}^{\mathrm{A}}$ prepared by solvothermal reaction. (C) TEM images of the MNBs.

Table S1. Catalytic activity (CA) and Specific activity (SA) of Au@Pd NZs and Au NPs.

\begin{tabular}{lll}
\hline Material & $\mathrm{CA}\left(\mu \mathrm{mol} \mathrm{min} \mathrm{mL}^{-1}\right)$ & $\mathrm{SA}\left(\mathrm{U} \mathrm{mg}^{-1}\right)$ \\
\hline $\mathrm{Au} @$ pd NZs & $1.25 \pm 0.097$ & $7.13 \pm 0.049$ \\
$\mathrm{Au}$ NPs & $0.24 \pm 0.06$ & $1.36 \pm 0.021$ \\
\hline
\end{tabular}

$\mathcal{E}$-molar absorption coefficients of TMB was $39,000 \mathrm{M}^{-1} \cdot \mathrm{cm}^{-1}$ 
Table S2. Comparison of the kinetic parameters $\left(K_{\mathrm{m}}\right.$ and $\left.V_{\max }\right)$ of $\mathrm{Au} @ \mathrm{Pd} \mathrm{NZs}$ and Au NPs.

\begin{tabular}{|c|c|c|c|}
\hline & & $K_{\mathrm{m}}(\mu \mathrm{M})$ & $V_{\max }(\mu \mathrm{M})$ \\
\hline \multirow[t]{2}{*}{$\mathrm{Au} @ \mathrm{Pd}$} & TMB & $0.63 \pm 0.005$ & $60.80 \pm 0.01$ \\
\hline & $\mathrm{H} 2 \mathrm{O} 2$ & $284 \pm 0.004$ & $79.60 \pm 0.02$ \\
\hline \multirow[t]{2}{*}{$\mathrm{AU}$} & TMB & $1.22 \pm 0.007$ & $3.69 \pm 0.007$ \\
\hline & $\mathrm{H} 2 \mathrm{O} 2$ & $21.60 \pm 0.005$ & $45.40 \pm 0.004$ \\
\hline
\end{tabular}

Table S3. Comparison of the kinetic parameters $\left(K_{\mathrm{m}}\right.$ and $\left.V_{\max }\right)$ of $\mathrm{Au} @ \mathrm{Pd}$ Probe and Horseradish peroxidase (HRP).

\begin{tabular}{cccc}
\hline & & $K_{\mathrm{m}}(\mu \mathrm{M})$ & $V_{\max }(\mu \mathrm{M})$ \\
$\mathrm{Au} @$ Pd Probe & TMB & $0.63 \pm 0.004$ & $59.56 \pm 0.03$ \\
HRP & TMB & $3.51 \pm 0.002$ & $55.50 \pm 0.005$ \\
\hline
\end{tabular}

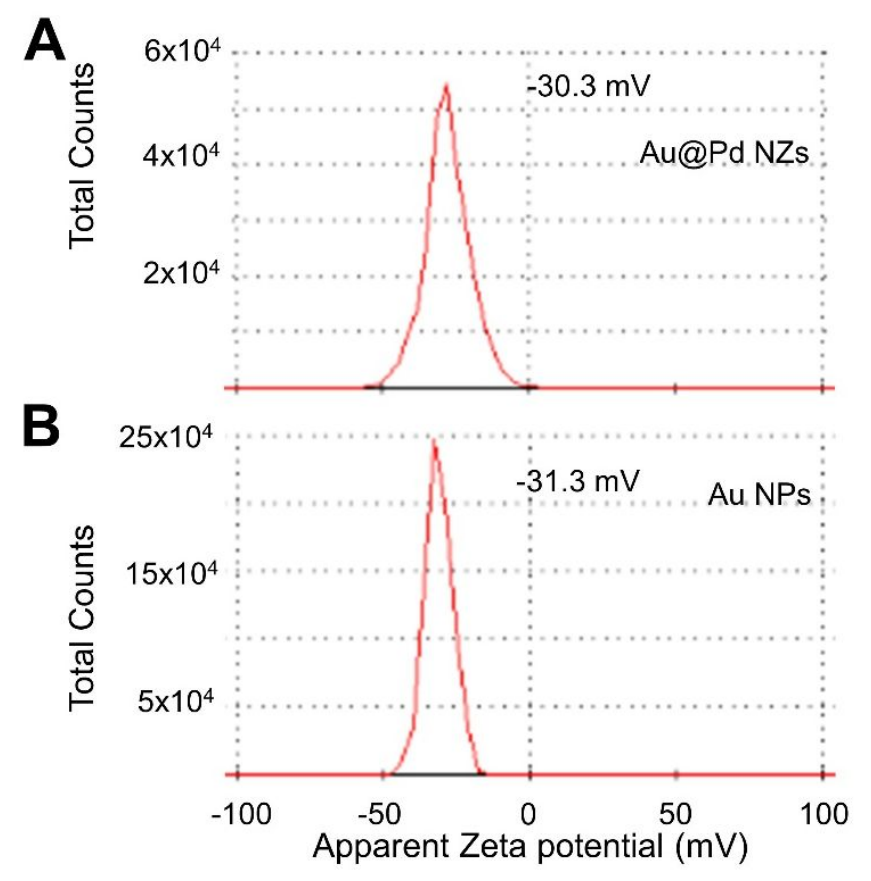




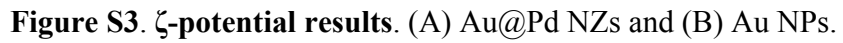

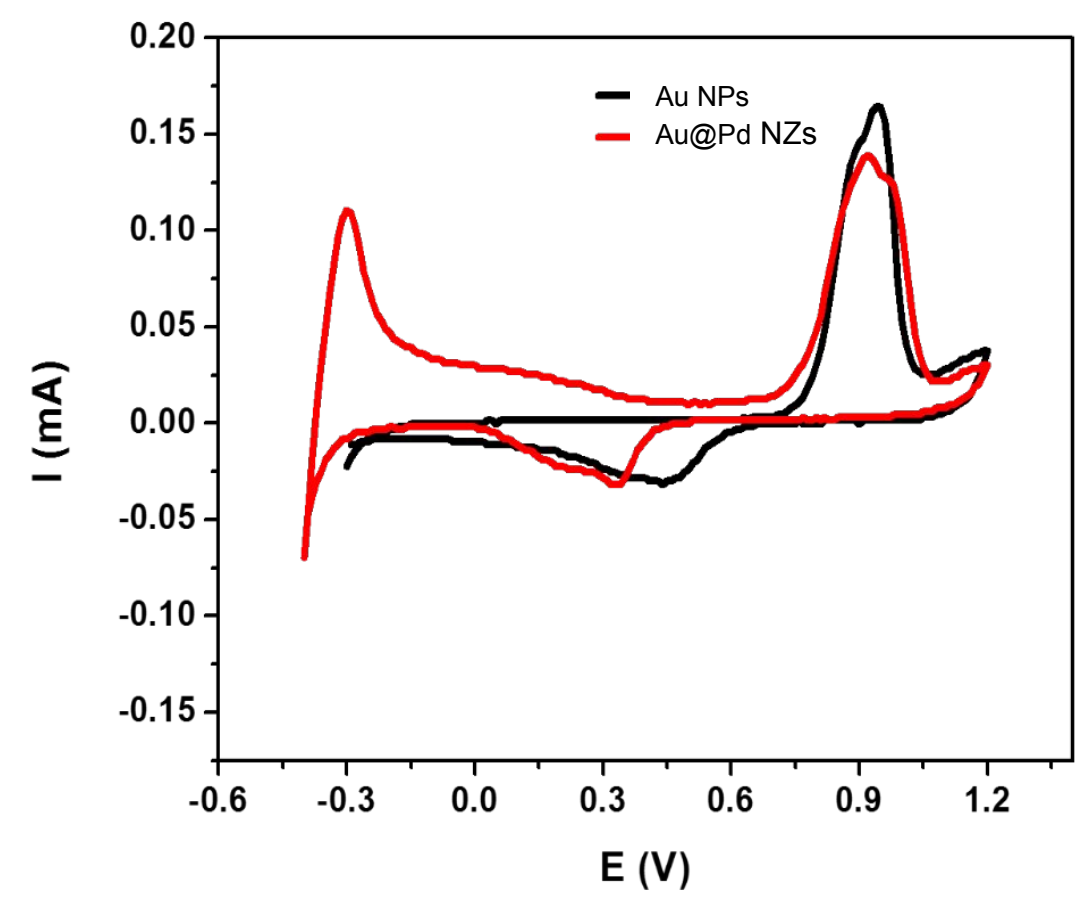

Figure S4. Cyclic voltammograms of Au/GCE (deposited with 13 nm Au colloids) and Au@Pd/GC electrodes (deposited with $\mathrm{Au} @ \mathrm{Pd} \mathrm{NZs}$ ) in $0.1 \mathrm{M} \mathrm{HCl}$ at a scan rate of $100 \mathrm{mVs}^{-1}$.

A
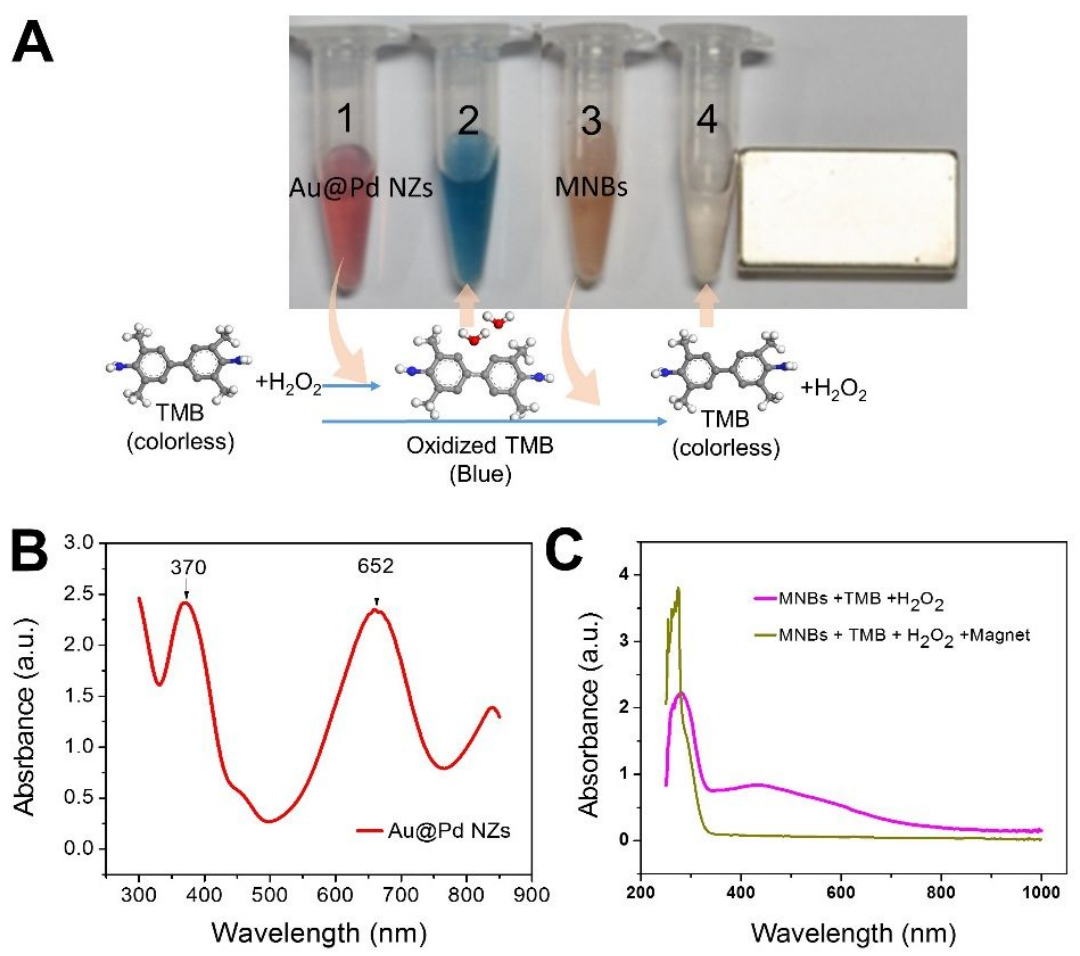
Figure S5. Chromogenic reaction. Photograph showing TMB oxidation by Au@Pd NZs (A1 and 2) and MNB (A3 and 4). (B) UV-Vis spectrometry of A2. (C) UV-Vis spectrometry of A3 and 4.
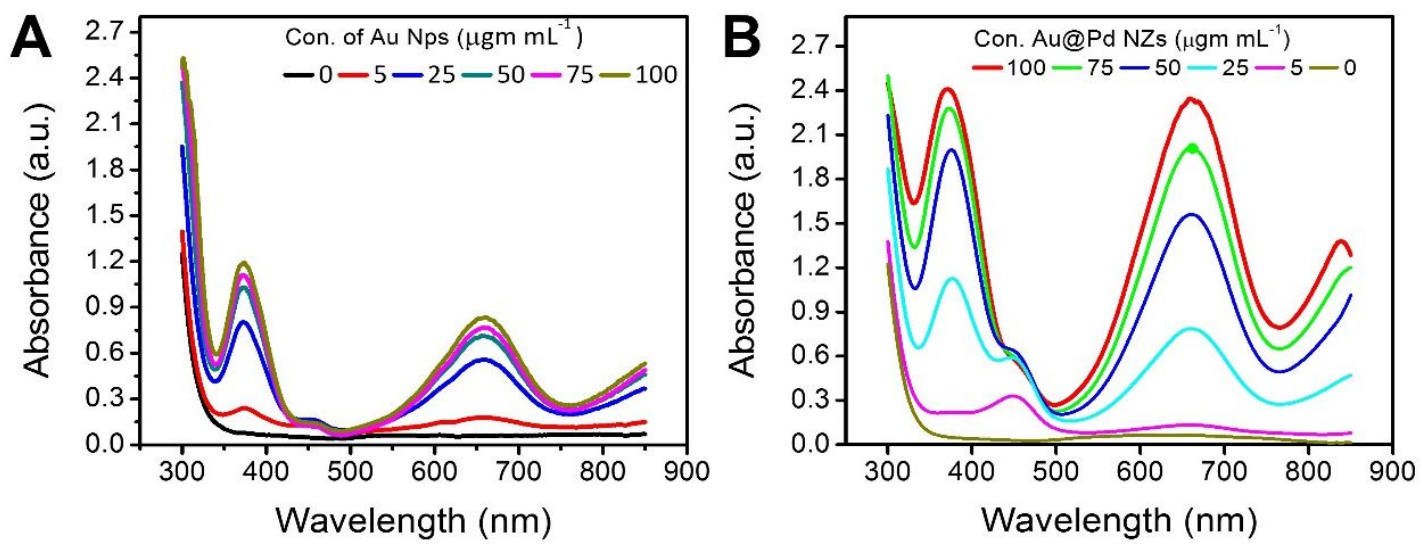

Figure S6. TMB oxidation peaks. Varying concentrations of (A) Au NPs. (B) Au@Pd NZs. Con denotes concentration of the nanoparticles
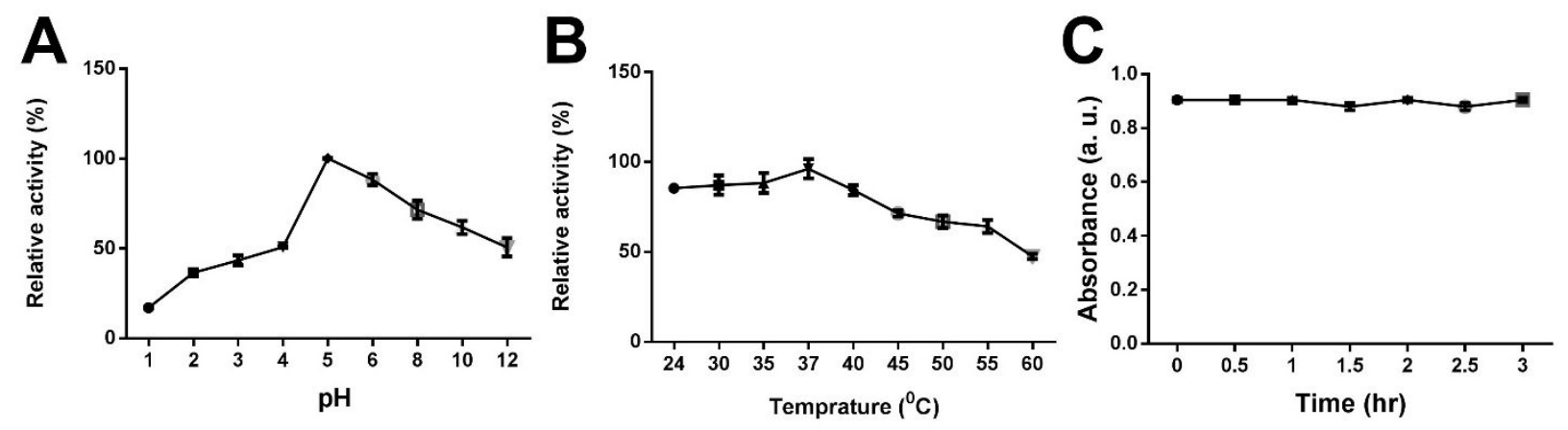

Figure S7. Effect of (A) pH (B) Temperature (C) Time on the peroxidase-like activity of the Au@Pd nanoenzyme. The displayed error bars symbolize the standard error from three independent experiments. 

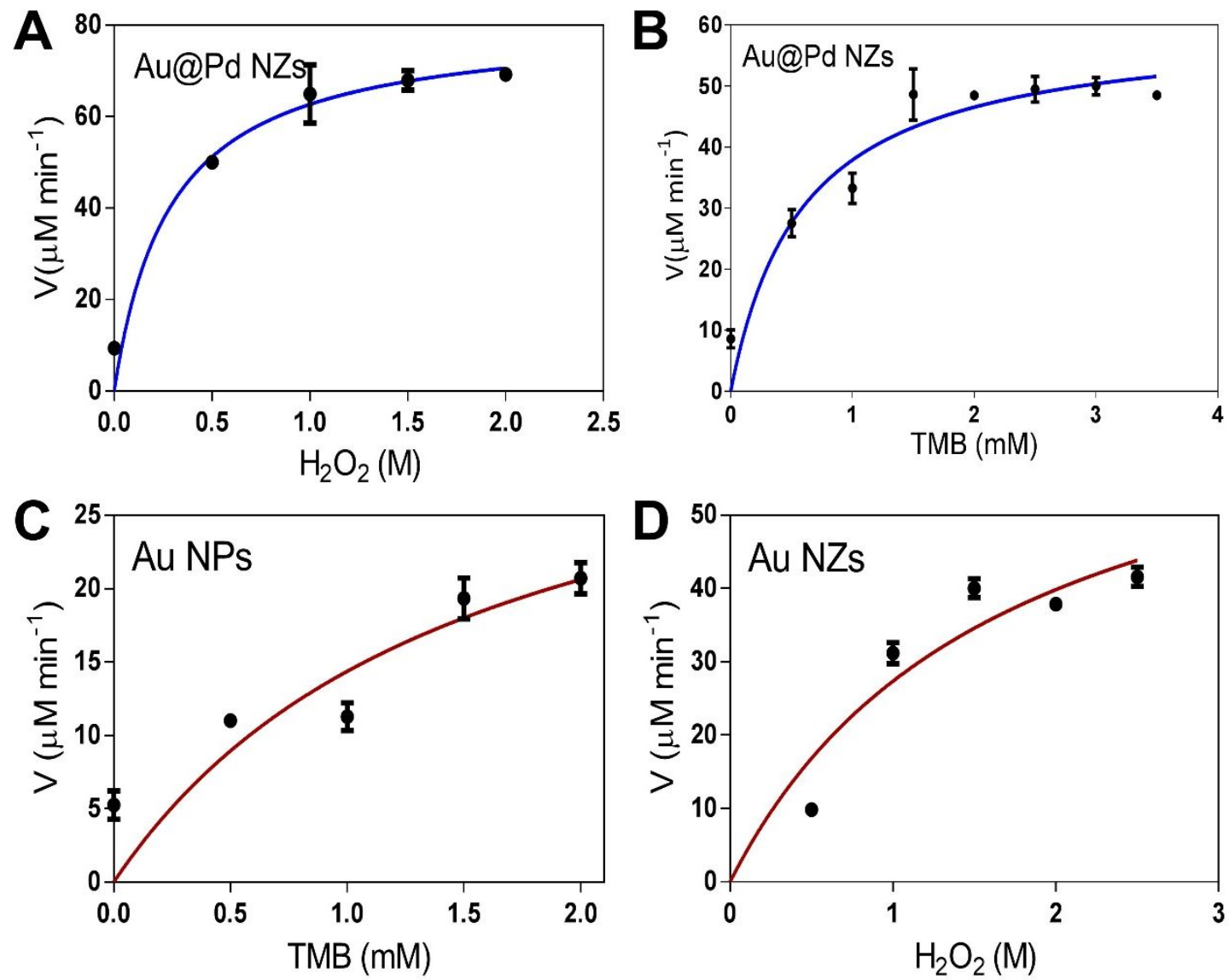


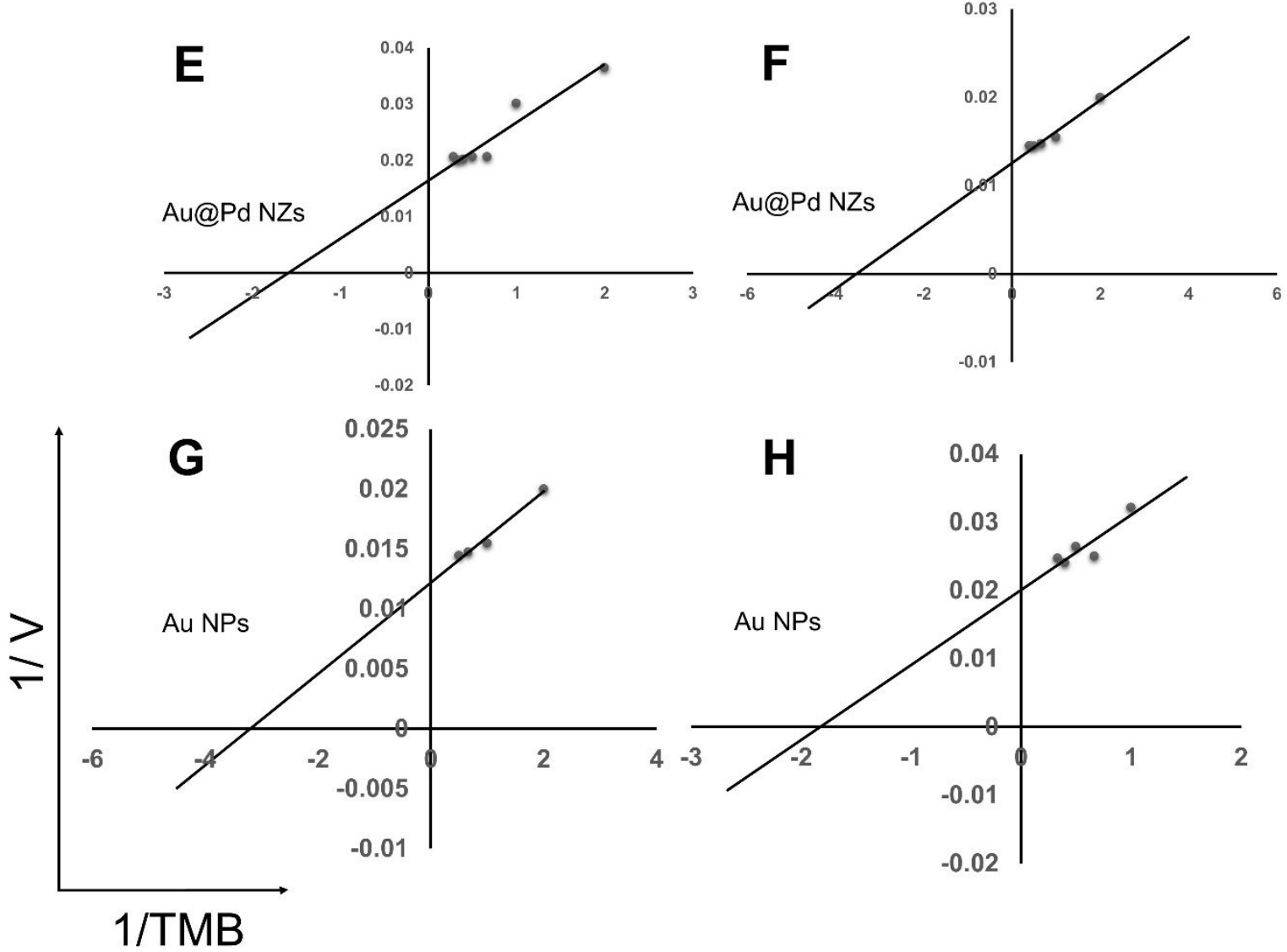

Figure S8. Characterization of the catalytic kinetics of peroxidase NZs. (A-D) Michaelis-Menten curves. (E-H) Double reciprocal plots made respectively from (A-D) Michaelis-Menten curves. The displayed error bars symbolize the standard error from three independent experiments.
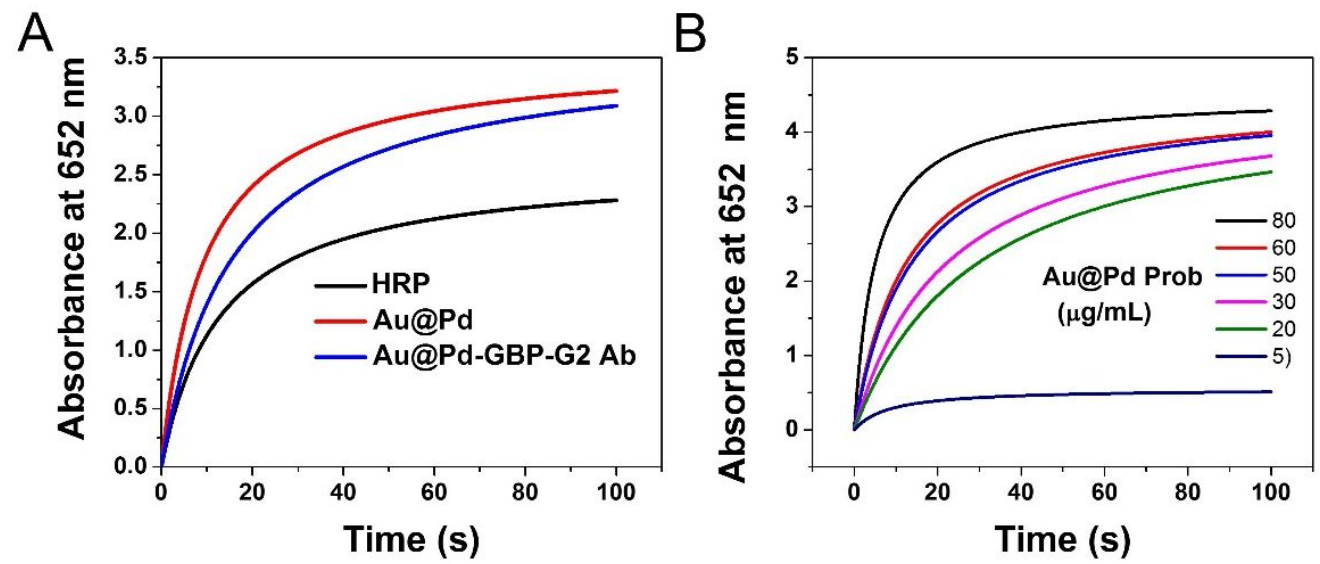

Figure S9. (A) Reaction time curve of Au@Pd (red), Au@Pd probe (Au@Pd-GBP-G2 Ab) (blue)and Horseradish peroxidase (HRP, black). (B) Concentration-dependent reaction time curves Au@Pd probe. 

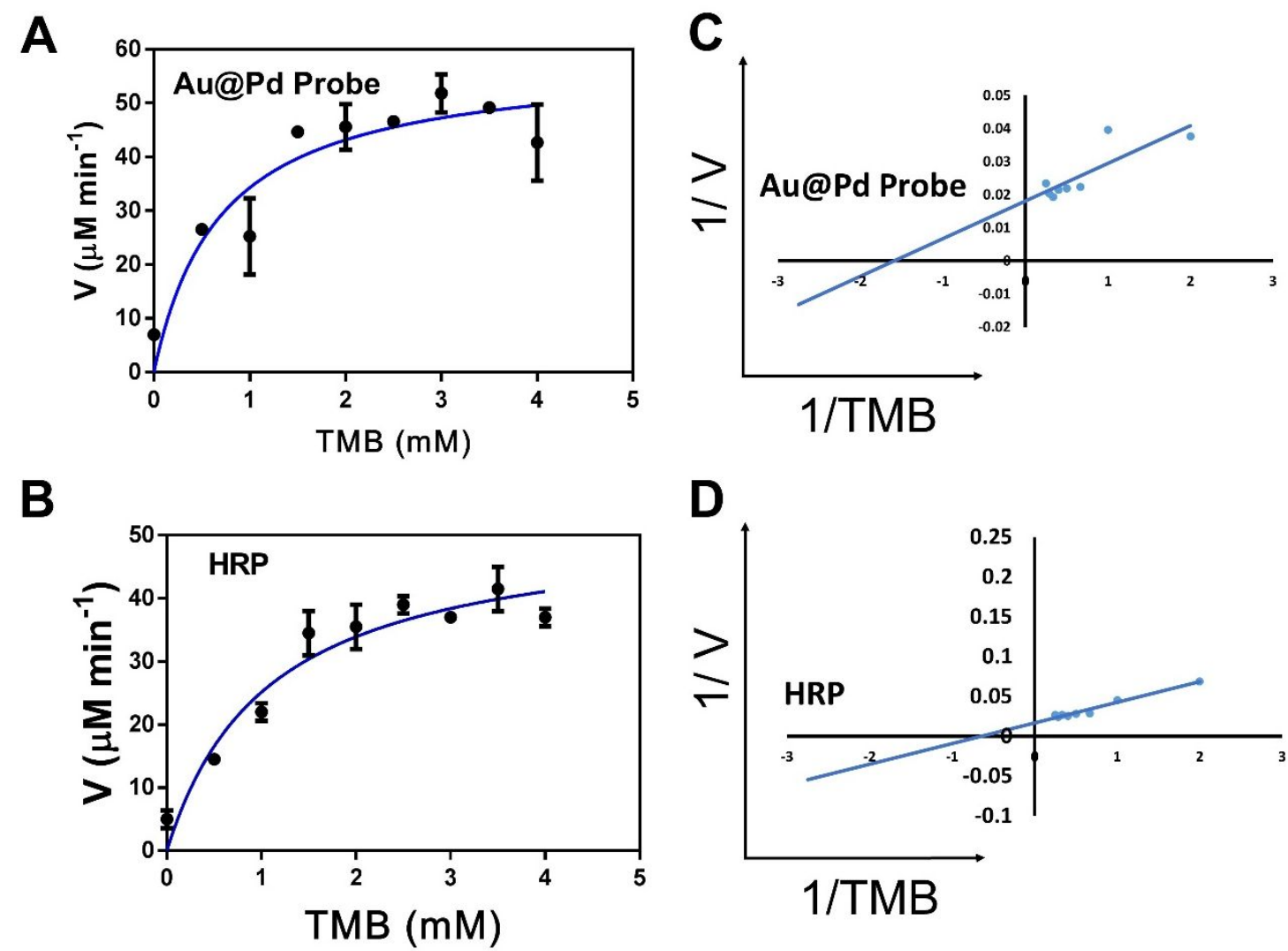

Figure S10. (A and B) Michaelis-Menten curves of $\mathrm{Au} @$ Pd probe and HRP respectively. (C and D) Double reciprocal plots made respectively from (A and B) Michaelis-Menten curves. The displayed error bars symbolize the standard error from three independent experiments. 

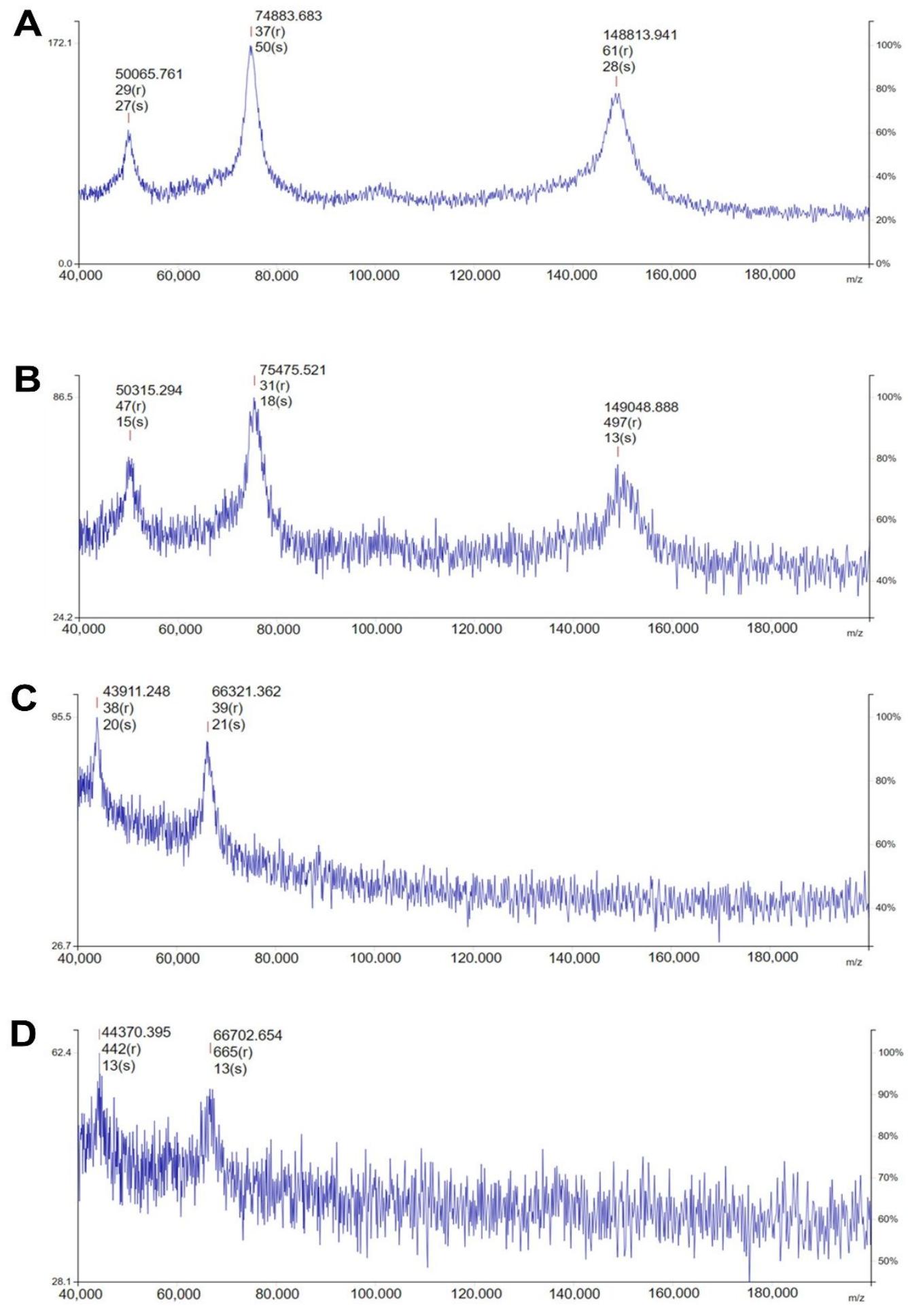

Figure S11. MALDI-TOF-MS spectra of (A) $10 \mu \mathrm{g}$ and (B) $1 \mu \mathrm{g}$ of a typical standard antibody protein (IgG), (C) purified antiCFP-10 antibody protein (GBP-G2), and (D) anti-CFP-10 conjugated Au@Pd NPs. 
The MALDI-MS matrix 2-nitrophloroglucinol (2-NPG) is able to generate multiple-charged protein peaks of high molecular weight proteins when prepared with specific additives such as $\mathrm{H}_{3} \mathrm{PO}_{4}$ and $\mathrm{HCl}{ }^{13}$. This effect was applied for the characterization of antibody proteins to overcome the difficulties with sensitivity of MALDI-TOF MS at high m/z range. For example, samples containing a standard antibody protein IgG (Figure. S8A and B) are able to produce a +2 charged protein peak at $\mathrm{m} / \mathrm{z} \sim 75,400$ and $\mathrm{a}+3$ charged peak at $\mathrm{m} / \mathrm{z} \sim 50,000$, with significantly greater $\mathrm{S} / \mathrm{N}$ ratio than the +1 charged peak $(\mathrm{m} / \mathrm{z}$ $\sim 149,000)$.

The same conditions were applied for the characterization of the purified anti-CFP-10 antibody protein conjugated $\mathrm{Au} @$ Pd NZs. In the obtained spectrum of the sample containing purified anti-CFP-10 antibody (Figure. S8C), a +2 charged peak at $\mathrm{m} / \mathrm{z} \sim 67,000$ and $\mathrm{a}+3$ charged peak at $\mathrm{m} / \mathrm{z} \sim 44,000$, both indicated that the molecular weight of the antibody is approximately $\sim 132 \mathrm{kDa}$. The singly charged protein peak is not observed due to the effect of 2-NPG matrix additives and high background noise in this $\mathrm{m} / \mathrm{z}$ region. On comparison, the same protein peaks were found in the spectrum of the washed anti-CFP-10 conjugated Au@Pd NZs samples, suggesting the antibody molecules were successfully conjugated to the Au@Pd particle surfaces.

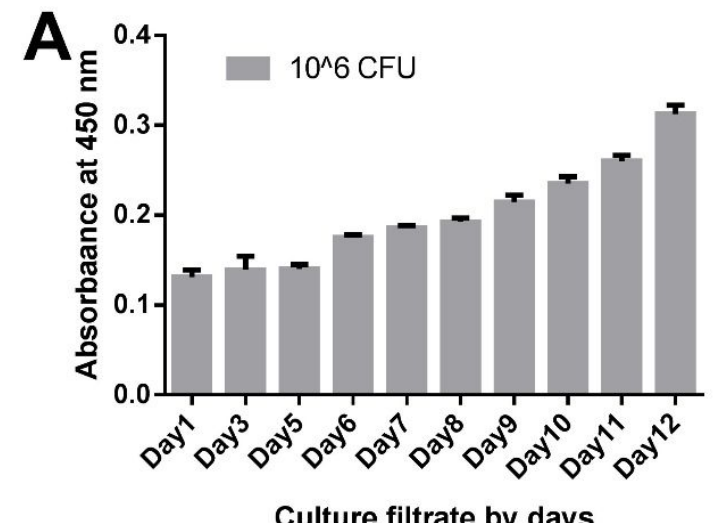

Culture filtrate by days

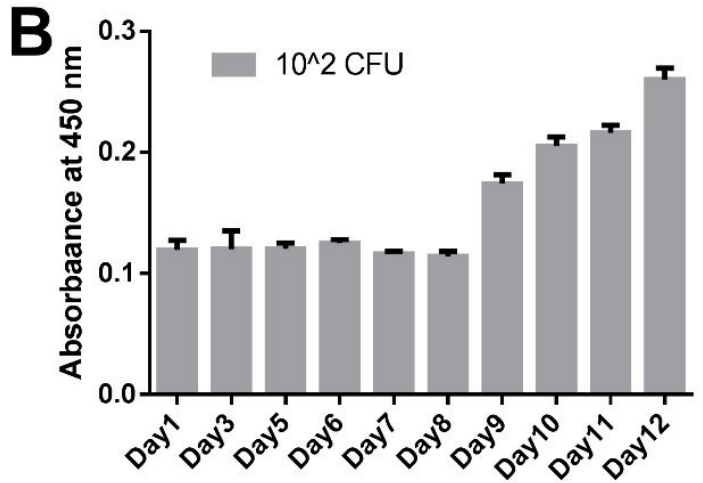

Culture filtrate by days

Figure S12. Detection of CFP-10 using Au@Pd NZ-based MNBs ELISA. Culture collected from an initial inoculum with (A) $10^{6} \mathrm{CFU}$. (B) $10^{2} \mathrm{CFU} \mathrm{mL} \mathrm{m}^{-1}$. The displayed error bars symbolize the standard error from three independent experiments. CFU stands for colony forming units of mycobacterium tuberculosis. 

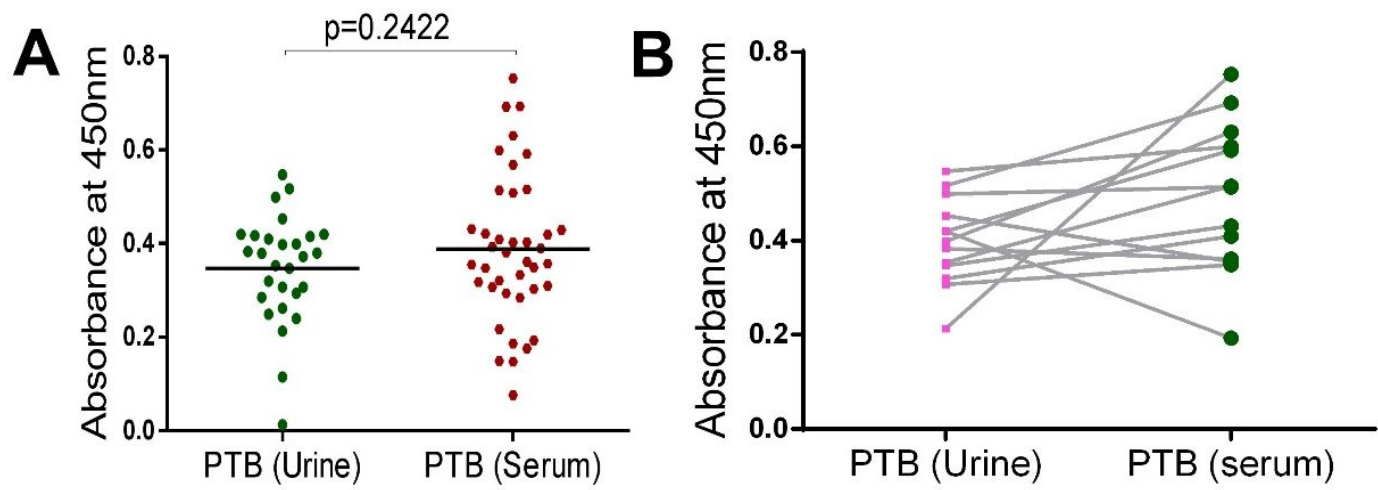

Figure S13. Comparison of the detected CFP-10 antigens. (A) Between urine and serum samples. (B) Urine and serum samples from same patients. In the scattered plot the horizontal line indicates the median value.

Table S4. Comparison of LOD of NZs-based ELISA

\begin{tabular}{|c|c|c|c|}
\hline Antigens & Immunoassay Methods & LOD & Ref. \\
\hline CFP-10 & $\begin{array}{l}\text { Ultrasensitive } \mathrm{Au} @ \mathrm{Pd} \\
\text { nanozyme-based magnetic } \\
\text { ELISA }\end{array}$ & $5.6 \times 10^{-12} \mathrm{~g} \mathrm{~mL}^{-1}$ & Current work \\
\hline CFP-10 & Au-based Plasmon & $0.1 \times 10^{-7} \mathrm{~g} \mathrm{~mL}^{-1}$ & 14 \\
\hline ESAT-6 & $\begin{array}{l}\text { Au NP-mediated high- } \\
\text { performance ELISA }\end{array}$ & $1 \mathrm{nM}$ & 15 \\
\hline ESAT-6 & $\begin{array}{l}\text { Antigen-antibody- based red } \\
\text { spectra shift in Au NPs }\end{array}$ & $1.25 \mathrm{nM}$ & 16 \\
\hline CFP-10:ESAT-6 & $\begin{array}{l}\text { Surface enhanced CdSe/ZnS } \\
\text { QD/SiNP electrochemical } \\
\text { immunosensor }\end{array}$ & $1.5 \times 10^{-10} \mathrm{~g} \mathrm{~mL}^{-1}$ & 17 \\
\hline CFP-10 & Traditional ELISA & $30 \mathrm{nM}$ & 15 \\
\hline
\end{tabular}


Table S5. Total clinical samples with respect to healthy control and active TB. Negative implies no response while positive means color change with respect to the application of $\mathrm{Au} @$ Pd-based MNB ELISA. The data shown are the mean \pm SD of at least three experiments.

\begin{tabular}{|c|c|c|c|}
\hline \multicolumn{4}{|c|}{ Serum samples } \\
\hline Diagnosis of MTB infection & Tested samples $(\mathrm{N})$ & Positive result (\%) & Negative result $(\%)$ \\
\hline Negative (Healthy) & 23 & (21) $91 \%$ & (2) $9 \%$ \\
\hline Positive (Active TB) & 40 & (37) $93 \%$ & (3) $8 \%$ \\
\hline \multicolumn{4}{|c|}{ Urine samples } \\
\hline Diagnosis of MTB infection & Tested samples $(\mathrm{N})$ & Positive result (\%) & Negative result $(\%)$ \\
\hline Negative (Healthy) & 21 & (20) $95 \%$ & (1) $5 \%$ \\
\hline Positive (Active TB) & 28 & (26) $93 \%$ & (2) $7 \%$ \\
\hline
\end{tabular}

Table S6. Accuracy, specificity, and sensitivity of Au@Pd-based MNB ELISA performed on clinical samples. The data shown are the mean $\pm \mathrm{SD}$ of at least three experiments.

\begin{tabular}{|c|c|c|c|c|}
\hline Serum & $\begin{array}{c}\text { Active } \mathrm{TB}(\mathrm{N}= \\
40)\end{array}$ & Sensitivity (\%) & Specificity (\%) & Accuracy $(\%)$ \\
\hline True positive & 37 & & & \\
\hline False positive & 2 & 93 & 91 & 92.1 \\
\hline True negative & 21 & & & \\
\hline False negative & 3 & & & \\
\hline Urine & $\begin{array}{c}\text { Active TB }(\mathrm{N}= \\
40)\end{array}$ & Sensitivity (\%) & Specificity (\%) & Accuracy (\%) \\
\hline True positive & 26 & & & \\
\hline False positive & 1 & 93 & 95 & 92 \\
\hline True negative & 20 & & & \\
\hline False negative & 2 & & & \\
\hline
\end{tabular}



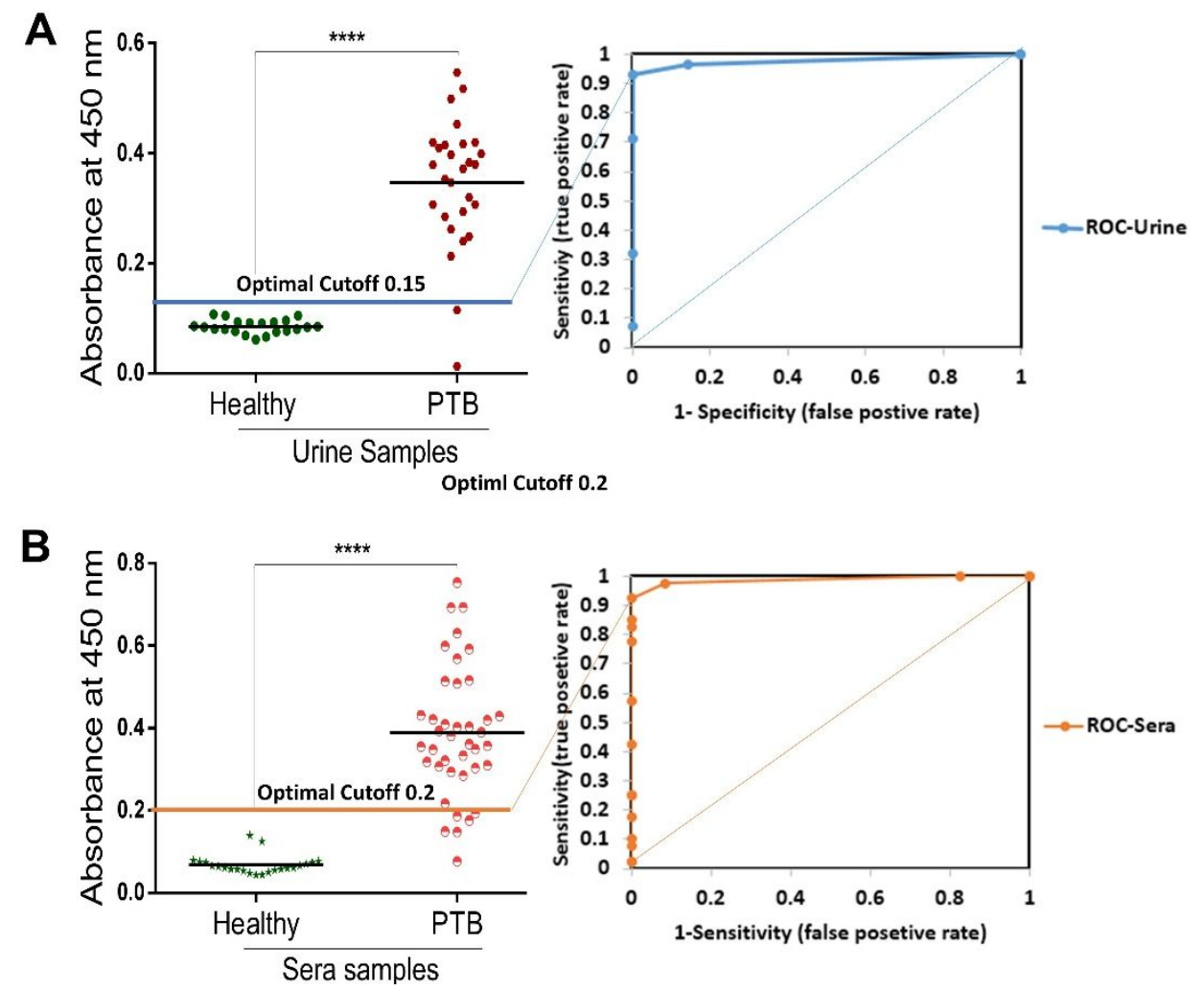

Figure S14. ROC curve generated from 'True positive' vs. 'false positive' Pulmonary tuberculosis. (A) Probable PTB vs. Healthy urine samples. (B) Probable PTB vs. Healthy sera samples. The horizontal plane across the scatter plot indicates the cut-off value for urine and sera samples. 


\section{Reference}

(1) Tufa, L. T.; Oh, S.; Kim, J.; Jeong, K.-J.; Park, T. J.; Kim, H.-J.; Lee, J. Electrochemical immunosensor using nanotriplex of graphene quantum dots, $\mathrm{Fe} 3 \mathrm{O} 4$, and Ag nanoparticles for tuberculosis. Electrochimica Acta 2018, 290, 369-377.

(2) Kim, J.; Lee, J.; Lee, K.-I.; Park, T. J.; Kim, H.-J.; Lee, J. Rapid monitoring of CFP-10 during culture of Mycobacterium tuberculosis by using a magnetophoretic immunoassay. Sensors and Actuators B: Chemical 2013, 177, 327-333.

(3) Welin, A.; Björnsdottir, H.; Winther, M.; Christenson, K.; Oprea, T.; Karlsson, A.; Forsman, H.; Dahlgren, C.; Bylund, J. CFP-10 from Mycobacterium tuberculosis selectively activates human neutrophils through a pertussis toxin-sensitive chemotactic receptor. Infection and immunity 2015, 83 (1), 205-213.

(4) Meher, A. K.; Bal, N. C.; Chary, K. V.; Arora, A. Mycobacterium tuberculosis H37Rv ESAT-6-CFP-10 complex formation confers thermodynamic and biochemical stability. The FEBS journal 2006, 273 (7), 1445-1462.

(5) Pai, M.; Denkinger, C. M.; Kik, S. V.; Rangaka, M. X.; Zwerling, A.; Oxlade, O.; Metcalfe, J. Z.; Cattamanchi, A.; Dowdy,

D. W.; Dheda, K. Gamma interferon release assays for detection of Mycobacterium tuberculosis infection. Clinical microbiology reviews 2014, 27 (1), 3-20.

(6) Kunst, H. Diagnosis of latent tuberculosis infection: the potential role of new technologies. Respiratory medicine 2006, 100 (12), 2098-2106.

(7) Dehghani, Z.; Hosseini, M.; Mohammadnejad, J.; Bakhshi, B.; Rezayan, A. H. Colorimetric aptasensor for Campylobacter jejuni cells by exploiting the peroxidase like activity of Au@Pd nanoparticles. Microchimica Acta 2018, 185 (10), 448.

(8) Singh, S.; Tripathi, P.; Kumar, N.; Nara, S. Colorimetric sensing of malathion using palladium-gold bimetallic nanozyme. Biosensors and Bioelectronics 2017, 92, 280-286.

(9) Yang, F.; Yang, Z.; Zhuo, Y.; Chai, Y.; Yuan, R. Ultrasensitive electrochemical immunosensor for carbohydrate antigen 19-9 using Au/porous graphene nanocomposites as platform and $\mathrm{Au} @ \mathrm{Pd}$ core/shell bimetallic functionalized graphene nanocomposites as signal enhancers. Biosensors and Bioelectronics 2015, 66, 356-362.

(10) Zhou, W.; Lee, J. Y. Highly active core-shell Au@ Pd catalyst for formic acid electrooxidation. Electrochemistry Communications 2007, 9 (7), 1725-1729.

(11) Skrabalak, S. E.; Chen, J.; Neretina, S.; Qin, D. Beyond the Gold Standard: Bimetallic Nanomaterials Bring New Properties and Functions. Particle \& Particle Systems Characterization 2018, 35 (5), 1800111.

(12) Oh, S.; Kim, J.; Tran, V. T.; Lee, D. K.; Ahmed, S. R.; Hong, J. C.; Lee, J.; Park, E. Y.; Lee, J. Magnetic nanozyme-linked immunosorbent assay for ultrasensitive influenza A virus detection. ACS applied materials \& interfaces 2018, 10 (15), 1253412543.

(13) Choi, H.; Lee, D.; Kim, Y.; Nguyen, H.-Q.; Han, S.; Kim, J. Effects of Matrices and Additives on Multiple Charge Formation of Proteins in MALDI-MS Analysis. Journal of The American Society for Mass Spectrometry 2019, 30 (7), 11741178.

(14) Mohd Bakhori, N.; Yusof, N. A.; Abdullah, J.; Wasoh, H.; Noor, M.; Suraiya, S.; Raston, A.; Hanun, N.; Mohammad, F. Immuno nanosensor for the ultrasensitive naked eye detection of tuberculosis. Sensors 2018, 18 (6), 1932.

(15) Lakshmipriya, T.; CB Gopinath, S.; Citartan, M.; Hashim, U.; Tang, T.-H. Gold nanoparticle-mediated high-performance enzyme-linked immunosorbent assay for detection of tuberculosis ESAT-6 protein. Micro and Nanosystems 2016, 8 (2), $92-98$. (16) Wang, F.-a.; Lakshmipriya, T.; Gopinath, S. C. Red Spectral Shift in Sensitive Colorimetric Detection of Tuberculosis by ESAT-6 Antigen-Antibody Complex: a New Strategy with Gold Nanoparticle. Nanoscale research letters 2018, 13 (1), 331.

(17) Mohd Bakhori, N.; Yusof, N. A.; Abdullah, J.; Wasoh, H.; Ab Rahman, S. K.; Rahman, A.; Fatimah, S. Surface Enhanced $\mathrm{CdSe} / \mathrm{ZnS} \mathrm{QD} / \mathrm{SiNP}$ Electrochemical Immunosensor for the Detection of Mycobacterium Tuberculosis by Combination of CFP10-ESAT6 for Better Diagnostic Specificity. Materials 2020, 13 (1), 149. 